Rize ilinde görev

yapmakta olan diş

hekimlerinin dental

travma yönetimi

konusunda bilgi, tutum

ve davranışlarının

değerlendirilmesi

\section{Evaluation of dentists' \\ knowledge, attitude and behavior about the management of dental trauma in Rize province}

\author{
Dr. Öğr. Üyesi Sema Aydinoğlu \\ Recep Tayyip Erdoğan Üniversitesi, \\ Diş Hekimliği Fakültesi, Pedodonti A.D., Rize \\ Orcid ID: 0000-0003-1490-8645

\section{Dr. Öğr. Üyesi İpek Arslan} \\ Recep Tayyip Erdoğan Üniversitesi, \\ Diş Hekimliği Fakültesi, Pedodonti A.D., Rize \\ Orcid ID: 0000-0002-8648-3554
}

\section{Arş. Gör. Dt. Zeynep Demirez}

Recep Tayyip Erdoğan Üniversitesi,

Diş Hekimliği Fakültesi, Pedodonti A.D., Rize

Orcid ID: 0000-0003-1614-1425

Geliş tarihi: 23 Eylül 2019

Kabul tarihi: 28 Ocak 2020

doi: 10.5505/yeditepe.2020.77598

\section{Yazışma adresi:}

Dr. Öğr. Üyesi Sema Aydınoğlu

RTEÜ Diş Hekimliği Fakültesi Pedodonti AD,

Rize, Türkiye

Tel: 05368381138

E-posta:semapilak@hotmail.com
ÖZET

Amaç: Rize ilinde görev yapmakta olan diş hekimlerinin dental travmalar karşısında bilgi, beceri ve tutumlarının değerlendirilmesi amaçlanmaktadır.

Gereç ve Yöntem: Bu çalışmaya Rize ilinde görev yapmakta olan 73'ü kadın ve 48'i erkek olmak üzere 121 hekim dahil edildi. Katıımcılara yüz yüze görüşme yöntemi ile uygulanan anket içerisinde toplam 34 sorudan oluşan üç bölüm yer aldı. Hekimlerin kişisel ve mesleki bilgileri, dental travma karşısında tutumları yüz yüze görüşme yöntemiyle değerlendirildi. Diş hekimliği eğitim seviyesine göre belirlenen gruplarda travma ile ilgili hekimlere yöneltilen soruların cevapları ki-kare testi kullanılarak analiz edildi.

Bulgular: Genel diş hekimlerinin \%48.1'inin kompoziti, uzmanlık öğrencilerinin \%69.6'sının fiberi ve uzmanların \%53.3'ünün ligatür telini splint materyali olarak tercih ettiği görüldü $(p<0.001)$. Ağız dışında 1 saatten az $(p=0.004)$ ve 1 saatten fazla $(p<0.001)$ kuru ortamda kalan kök ucu kapalı daimi diş avülsiyon ve ekstrüzyon ( $p=0.004)$ vakaları, daimi diş mine kırığı $(p=0.027)$ ve alveol kırığı $(p=0.013)$ olguları ile süt dişi ekstrüzyon ve avülsiyon ( $p=0.013, p=0.017$ ) yaralanmaları karşısındaki tedavi yaklaşımları ile diş hekimliği eğitim seviyesi arasında istatistiksel olarak anlamlı bir fark gözlendi. Mine kırığı $(p<0.001)$ ve komplike olmayan kuron kırığı $(p<0.001)$ vakaları ile intrüzyon ve alveol kırığı $(p=0.018, p=0.002)$ yaralanmalarına müdahalede bulunma durumu açısından katıımcılar arasında istatistiksel olarak anlamlı bir ilişki tespit edildi.

Sonuç: Diş hekimlerinin dental travma konusunda yeterli bilgiye sahip oldukları ancak çeşitli travma tiplerinde müdahaleden kaçındıkları görüldü. Bu çalışmanın sınırları dahilinde, diş hekimlerinin yetersiz oldukları konular ile ilgili teorik ve uygulamalı eğitimlerin verilmesi önerilebilir.

Anahtar kelimeler: Dental travma, avülsiyon, lüksasyon, diş hekimi, bilgi

SUMMARY

Aim: The purpose of this study was to evaluate the dentists' knowledge, attitude and behaviour regarding dental trauma in Rize Province.

Materials and Methods: Total of 121 dentists, 73 females and 48 males, were included in this study. A questionnaire consisted of 34 questions and three sections was applied face to face. Personal and professional knowledge and attitudes about dental trauma were evaluated. The association between the dentists at different education level and trauma intervention were analyzed with chi-square test.

Results: Most of general dentists (48.1\%), postgraduate students (69.6\%) and specialists (53.3\%) preferred composite, fiber and ligature wire as splint materials, respectively $(p<0.001)$. There was statistically significant association between dental education level with permanent extrusion $(p=0.004)$ and avulsion cases with closed apex in dry environment less than 1 hour $(p=0.004)$ and more than 1 hour $(p<0.001)$ outside the mouth, enamel fracture of permanent tooth $(p=0.027)$ and 
alveolar fracture $(p=0.013)$, primary tooth extrusion $(p=$ $0.013)$, and avulsion injuries ( $p=0.017$ ). Also, statistically significant relationship was found between dental education level and management of enamel fracture $(p<0.001)$, uncomplicated crown fracture $(p<0.001)$, intrusion $(p=$ $0.018)$ along with alveolar fracture $(p=0.002)$ injuries.

Conclusion: Dentists had sufficient knowledge about dental trauma but avoided intervention in various types of traumatic dental injuries. With in the limits of this study, additional theoretical and practical training on the emergency treatment of cases.may be recommended.

Keywords: Dental trauma, avulsion, luxation, dentist, knowledge

\section{GiRiş}

Travmatik dental yaralanmalar (TDY) okul öncesi ve okul dönemindeki çocuklarda sıklıkla karşılaşılan ciddi dental problemlerin başında gelmektedir ${ }^{1}$. Araştırmanın yapıldığı ülkeye, bölgenin coğrafik konumuna, mevsimsel değişikliklere, çalışmanın tipine, kültürel davranışlara, yaşa ve cinsiyete göre farklılıklar gösteren TDY'nin prevalansı \%12,6 ile \%46 arasında değişen oranlarda rapor edilmiştir. ${ }^{1-3}$ TDY genellikle trafik kazaları, dövüş sporları veya oyunları, çarpışma ve düşme sonucu meydana gelmektedir. ${ }^{1,4-6}$ Dental travmaya maruz kalan süt dişlerinin daha çok ev ortamında, daimi dişlerin ise ev ve okul çevresinde yaralandığı kaydedilmiştir. ${ }^{4}$

Ülkemizde TDY sebebi ile gelen hastaların ilk başvurduğu yerler devlete bağlı veya özel hizmet veren hastanelerin acil poliklinikleri, aile sağlığı merkezleri, ağız ve diş sağlığı merkezleri (ADSM), diş hekimliği fakülteleri ve özel diş klinikleri olabilmektedir. Bu merkezlerde çalışan diş hekimleri tarafından dental yaralanmalara hızlı, etkin ve doğru acil müdahalenin yapılması; ileride olması muhtemel fonksiyonel, estetik, sosyal, psikolojik problemlerin önüne geçilmesini veya en aza indirgenmesini sağlamaktadır. ${ }^{2}$ Ancak yapılan çalışmalar diş hekimlerinin dental travma konusundaki bilgilerinin yeterli olmadığını göstermektedir., 5,-9 Travmaya uğramış dişlerin prognozunda süratli ve doğru tedavi yaklaşımının hayati önem taşıdığı belirtilmektedir. ${ }^{10}$ Erken müdahale ve uygun tedavi planlaması ile komplike/komplike olmayan kuron/kök kırıkları, lüksasyon yaralanmaları ve özellikle avülsiyon olgularında travmaya uğrayan diş başarılı bir şekilde ağızda tutulabilmektedir. Geçen zamanın kritik değere sahip olduğu TDY ile gelen hastalara yetersiz, yanlış ve bilinçsizce müdahalede bulunmak veya hiçbir müdahalede bulunmamak yapılacak olan tedavinin daha karmaşık bir hal almasına ve tedavi masraflarının artmasına neden olmaktadır. ${ }^{11}$ Ayrıca hekimlerin dental travma karşısında yaptıkları herhangi bir hatalı veya eksik müdahale; diş renginde değişiklik, mobilite, okluzyon bozuklukları, hassasiyet problemleri, kökte veya kemikte rezorpsiyon, pulpal inflamasyon ve nekroz nihayetinde diş kaybı ile sonuçlanabilmektedir. ${ }^{12}$
Bu çalışmanın amacı Rize ilinde görev yapmakta olan diş hekimlerinin dental travma konusunda bilgi, beceri ve tutumlarını değerlendirmek ve bu hususta farkındalık oluşturmaktır.

\section{GEREÇ ve YÖNTEM}

\section{Etik Kurul Onayı}

Çalışma için gerekli etik kurul onayı Recep Tayyip Erdoğan Üniversitesi Tıp Fakültesi Girişimsel Olmayan Klinik Araştırmalar Etik Kurulu'ndan alındı (Karar No: 2018/106). Etik kurul tarafından onaylanan bilgilendirilmiş onam formları her katılımcıya imzalatıldı.

\section{Araştırmanın Şekli ve Yeri}

Rize ilinde diş hekimliği fakültesi, ADSM, diğer kamu kurumları, özel muayenehane ve polikliniklerde görev yapmakta olan il Sağlık Müdürlüğü'ne kayıtlı diş hekimi sayısının 137 olduğu bilgisine ulaşıldı. Araştırmacılar diş hekimlerine çalışmanın niteliği ve amacını açıklayarak gönüllülük ilkesini vurguladı. Aralarında doğum izninde olanların da yer aldığı 16 hekim çalışmada yer almak istemediği için 121 hekim çalışmaya dahil edildi.

\section{Anket Uygulaması}

Anket formları araştırmacılar tarafından yüz yüze görüşme yöntemiyle hekimlerin görev yapmakta oldukları kurumlarda dolduruldu. Kesin bir gizliliğin sağlanabilmesi için katılımcılardan isim, telefon numarası gibi kişisel bilgiler istenmedi. Anket formları çoktan seçmeli 34 sorunun bulunduğu üç bölüm halinde yapılandırıldı.

Birinci bölümde yaş, cinsiyet, meslekte hizmet süresi gibi kişisel bilgilerin yanında; 'Dental travma konusunda bilgilerinizin yeterli olduğunu düşünüyor musunuz?', 'Dental travma ile başvuran hastaya müdahalede bulunur musunuz?', 'Kliniğinizde splint yapıyor musunuz?' ve 'Kliniğinizde splint materyali olarak ne kullanıyorsunuz?' şeklinde mesleki bilgileri içeren sorulara yer verildi.

Anketin ikinci bölümünde kuron kırıkları, lateral lüksasyon, ekstrüzyon, intrüzyon ve alveol kırığı ile ilgili olgu fotoğrafları ve ilgili sorular yer aldı. Üçüncü bölüm ise süt dişlerinde lüksasyon, ekstrüzyon ve avülsiyon gibi travma tipleri konusunda hekimlerin bilgi düzeylerini ölçmeye yönelik sorulardan oluşturuldu.

Anket uygulaması tamamlandıktan sonra hekimlere 'Dental travma konusunda eğitim almak istermisiniz?' sorusu soruldu.

\section{İstatistiksel Analiz}

İstatistiksel değerlendirme için IBM SPSS Statistics 21.0 (IBM Corp. Released 2012. IBM SPSS Statistics for Windows, Version 21.0. Armonk, NY: IBM Corp.) programı kullanıldı. Çalışmaya katılan hekimlerin yaş, cinsiyet ve tecrübe durumları tanımlayıcı istatistiksel yöntemler ile analiz edildi. Diş hekimliği eğitim seviyesine göre belirlenen gruplarda travma ile ilgili hekimlere yöneltilen soruların cevapları ki-kare testi kullanılarak karşılaştırıldı. İstatistiksel anlamlılık düzeyi $p<0,05$ olarak kabul edildi. 


\section{BULGULAR}

Rize ilinde diş hekimliği fakültesi, ADSM, diğer kamu kurumları, özel muayenehane ve polikliniklerde görev yapmakta olan ve çalışmamıza katılan 121 diş hekiminin 56'sının genel diş hekimi, 42'sinin uzmanlık öğrencisi ve 23'ünün uzman diş hekimi olduğu belirlendi. Hekimlerin 73'ünün (\% 60,3) kadın, 48'inin (\% 39,7) ise erkeklerden oluştuğu saptandı. Araştırmada yer alan diş hekimlerinin çoğunluğunun (\% 67,8) 24-34 yaş aralığında olduğu, 54 yaş üzeri diş hekimlerinin (\% 14,3) hiçbirinin uzmanlık eğitimi almadığı tespit edildi (Tablo 1).

Tablo 1. Çalışmaya katılan hekimlerin cinsiyet, yaş ve tecrübeye göre dağılımı $(n=121)$.

\begin{tabular}{|l|c|c|c|c|}
\hline & $\begin{array}{c}\text { Genel Diş } \\
\text { Hekimi } \\
\text { n (\%) }\end{array}$ & $\begin{array}{c}\text { Uzmanllk } \\
\text { Ögrencisi } \\
\mathbf{n}(\%)\end{array}$ & $\begin{array}{c}\text { Uzman } \\
\mathbf{n}(\%)\end{array}$ & $\begin{array}{c}\text { Toplam } \\
\mathbf{n}(\%)\end{array}$ \\
\hline Cinsiyet & & & & \\
\hline Kadın & $26(46,4)$ & $32(76,2)$ & $15(65,2)$ & $73(60,3)$ \\
\hline Erkek & $30(53,6)$ & $10(23,8)$ & $8(34,8)$ & $48(39,7)$ \\
\hline Yaş & \multicolumn{5}{|l}{} & \\
\hline $24-34$ & $24(42,9)$ & $42(100)$ & $16(69,6)$ & $82(67,8)$ \\
\hline $35-44$ & $18(32,1)$ & $0(0)$ & $6(26,1)$ & $24(19,8)$ \\
\hline $45-54$ & $6(10,7)$ & $0(0)$ & $1(4,3)$ & $7(5,8)$ \\
\hline$>54$ & $8(14,3)$ & $0(0)$ & $0(0)$ & $8(6,6)$ \\
\hline Tecrübe (yl) & & & & \\
\hline $1-5$ & $19(33,9)$ & $41(97,6)$ & $3(13,0)$ & $63(52,1)$ \\
\hline $6-10$ & $7(12,5)$ & $1(2,4)$ & $11(47,8)$ & $19(15,7)$ \\
\hline $11-16$ & $9(16,1)$ & $0(0)$ & $7(30,4)$ & $16(13,2)$ \\
\hline$>16$ & $21(37,5)$ & $0(0)$ & $2(8,7)$ & $23(19,0)$ \\
\hline
\end{tabular}

Tablo 2. Diş hekimlerinin dental travma ile ilgili sorulara verdikleri cevapların dağılımı.

\begin{tabular}{|c|c|c|c|c|}
\hline & $\begin{array}{l}\text { Genel Diş } \\
\text { Hekimi } \\
\text { n (\%) }\end{array}$ & $\begin{array}{c}\text { Uzmanlık } \\
\text { Öğrencisi } \\
\text { n (\%) }\end{array}$ & $\begin{array}{c}\text { Uzman } \\
\text { n (\%) }\end{array}$ & $p$ değeri \\
\hline \multicolumn{5}{|c|}{ Dental travma konusunda bilgilerinizi y eterli görüyor musunuz? } \\
\hline Evet & $25(44,6)$ & $14(33,3)$ & $14(60,9)$ & \multirow{2}{*}{0,100} \\
\hline Hayır & $31(55,4)$ & $28(66,7)$ & $9(39,1)$ & \\
\hline \multicolumn{5}{|c|}{ Dental travma ile karşlaş̧ı̆ınızda genellikle müdahalede bulunur musunuz? } \\
\hline Evet & $38(67,9)$ & $33(78,6)$ & $16(69,6)$ & \multirow{2}{*}{0,487} \\
\hline Hayır & $18(32,1)$ & $9(21,4)$ & $7(30,4)$ & \\
\hline \multicolumn{5}{|c|}{ Kliniğinizde splint uygulaması yapıyor musunuz? } \\
\hline Evet & $26(46,4)$ & $23(54,8)$ & $16(69,6)$ & \multirow{2}{*}{0,170} \\
\hline Hayır & $30(53,6)$ & $19(45,2)$ & $7(30,4)$ & \\
\hline \multicolumn{5}{|c|}{ Kliniğinizde splint materyali olarak aşağıdakilerden hangisini kullanıyorsunuz? } \\
\hline Ligatïr teli & $10(37,0)$ & $5(21,7)$ & $8(53,3)$ & \multirow{3}{*}{$<0,001 *$} \\
\hline Kompozit rezin & $13(48,1)$ & $2(8,7)$ & $1(6,7)$ & \\
\hline Fiber & $4(14,8)$ & $16(69,6)$ & $6(40,0)$ & \\
\hline
\end{tabular}

*ki kare testi; $\mathrm{p}<0,05$

Tablo 2'de yer alan 'Dental travma konusunda bilgilerinizi yeterli görüyor musunuz?',

‘Dental travma ile karşılaştığınızda genellikle müdahalede bulunur musunuz?' ve 'Kliniğinizde splint yapıyor musunuz?' sorularına verilen yanıtlar arasında istatistiksel olarak anlamlı bir fark bulunamadı. Diş hekimlerinin \% 48,1'inin kompoziti, uzmanlık öğrencilerinin \% 69,6'sının fiberi ve uzmanların \% 53,3'ünün ligatür telini splint materyali olarak tercih ettiği görüldü $(p<0,001)$.

Dental avülsiyon yaralanmaları ile ilgili Tablo 3'te sorulan 'Avülse diş hangi şartlarda muhafaza edilmelidir?',
Tablo 3. Diş hekimlerinin daimi diş avülsiyon yaralanmaları ile ilgili sorulara verdikleri cevapların dağılımı.

\begin{tabular}{|c|c|c|c|c|}
\hline & $\begin{array}{c}\text { Genel Dis } \\
\text { Hekimi } \\
\text { n (\%) }\end{array}$ & $\begin{array}{l}\text { Uzmantlk } \\
\text { Ögrencisi } \\
\text { n (\%) }\end{array}$ & $\begin{array}{l}\text { Uzman } \\
\mathbf{n}(\%)\end{array}$ & $\stackrel{p}{\text { değeri }}$ \\
\hline \multicolumn{5}{|l|}{ Avülsse diṣ hangi şartlarda muhafaza edilmelidir? } \\
\hline Süt içerisinde & $31(55,4)$ & $30(71,4)$ & $16(69,6)$ & \multirow{3}{*}{0,149} \\
\hline $\begin{array}{l}\text { Serum fizyolojik içerisinde } \\
\text { Ağzicerisinde }\end{array}$ & $10(17,9)$ & $1(2,4)$ & $2(8,7)$ & \\
\hline \multirow{2}{*}{\multicolumn{5}{|c|}{ Kök ucu açık avülse dişin ağı̆u dışnda 1 saatten az kuru ortamda kaldığı olguya yaklaşımıız nasıl olur? }} \\
\hline & & & & \\
\hline Müdahale ederim. & $22(39,3)$ & $26(61,9)$ & $10(43,5)$ & \multirow{2}{*}{0,760} \\
\hline Müdahale etmesi için uzmana yörlendiririm. & $34(60,7)$ & $16(38,1)$ & $13(56,5)$ & \\
\hline \multicolumn{5}{|c|}{ 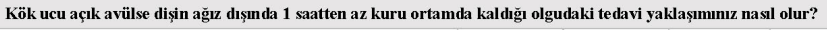 } \\
\hline $\begin{array}{l}\text { Disis sokete yerlesstirip } 2 \text { hafta boyunca esnek splint uygular ve } \\
\text { sistemik antibiyotik vererek apeksi kapanana kadar takip ederim. }\end{array}$ & $32(57,1)$ & $29(69)$ & $17(73,9)$ & \multirow{4}{*}{0,225} \\
\hline $\begin{array}{l}\text { Disis sokete yerleştirip } 2 \text { hafta boyunca rijit splint uygular ve } \\
\text { sistemik antibiyotik vererek apeksi kapanana kadar takip ederim. }\end{array}$ & $3(5,4)$ & $3(7,1)$ & $2(8,7)$ & \\
\hline Disis sokete yerlestitip 2 hafta boyunca esnek splint uygular ve 7 - & $13(23,2)$ & $9(21,4)$ & $1(4,3)$ & \\
\hline $\begin{array}{l}\text { lo gun tçensinde ka } \\
\text { Bilmiyorum. }\end{array}$ & $8(14,3)$ & $1(2,4)$ & $3(13)$ & \\
\hline \multicolumn{5}{|c|}{ Kök ucu açık avülse dişin ağız dışında 1 saatten fazla kuru ortamda kaldığ olguya yaklaşımınız nasıl olur? } \\
\hline Kendim müdahale ederim. & $12(21,4)$ & $17(40,5)$ & $10(43,5)$ & \multirow{2}{*}{0,600} \\
\hline Müdahale etmesi için uzmana yönlendiririm. & $44(78,6)$ & $25(59,5)$ & $13(56,5)$ & \\
\hline \multicolumn{5}{|c|}{ 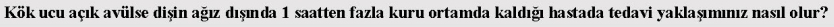 } \\
\hline $\begin{array}{l}\text { Disi hemen reimplante ederek } 4 \text { hafta boyunca esnek splint } \\
\text { uygularm. }\end{array}$ & $0(0)$ & $0(0)$ & $1(4,3)$ & \multirow{5}{*}{0,187} \\
\hline $\begin{array}{l}\text { Disinn üzerindeki artklart temizleyip \% 2'lik NaF veya } \\
\text { doks sisiklin cözeltisinde beklettikten sonra disi reimylante eder ve }\end{array}$ & $7(125)$ & $4(95)$ & $3(13)$ & \\
\hline $\begin{array}{l}4 \text { hafta boyunca rijit splint uygularmm. } \\
\text {. }\end{array}$ & & & & \\
\hline $\begin{array}{l}\text { Disisin üzerindeki arthklart temizleyip } \% 2 \text { 'lik NaF veya doksisiklin } \\
\text { côzeltisinde beklettikten sonra diși reimplante eder ve } 4 \text { hafta } \\
\text { boyunca esnek splint uygularım. }\end{array}$ & $37(66,1)$ & $33(78,6)$ & $12(52,2)$ & \\
\hline Bilmiyorum. & $12(21,4)$ & $5(11,9)$ & $7(30,5)$ & \\
\hline \multicolumn{5}{|c|}{ Kök ucu kapalı avülse diş̧in ağgz dışında 1 saatten az kuru ortamda kaldığı olguya yaliaşıımımz nasıl olur? } \\
\hline Kendim müdahale ederim. & $26(46,4)$ & $25(59,5)$ & $11(47,8)$ & \multirow{2}{*}{0,411} \\
\hline Müdahale etmesi için uzmana yörlendiririm. & $30(53,6)$ & $17(40,5)$ & $12(52,2)$ & \\
\hline \multicolumn{5}{|c|}{ Kök ucu kapalı avülse dişin ağız dışıda 1 saatten az kuru ortamda kaldığı olguda tedavi yaklaşımınız nasıl olur? } \\
\hline $\begin{array}{l}\text { Disis sokete yerleștirip } 2 \text { hafta boyunca esnek splint uygular ve } \\
\text { sistemik antibibotik vererek } 7-10 \text { gün içerisinde kanal tedavisine } \\
\text { başlarmm. }\end{array}$ & $31(55,4)$ & $37(88,1)$ & $16(69,6)$ & \multirow{4}{*}{$0,004^{*}$} \\
\hline $\begin{array}{l}\text { Disis sokete yerlestirip } 2 \text { hafta boyunca rijit splint uygular ve } \\
\text { sistemik antibiyotik vererek } 7-10 \text { gün içerisinde kanal tedavisine }\end{array}$ & $13(23,2)$ & $4(9,5)$ & $6(26,1)$ & \\
\hline & & & & \\
\hline Bilmiyorum. & $12(21,4)$ & $1(2,4)$ & $1(4,3)$ & \\
\hline \multicolumn{5}{|c|}{ 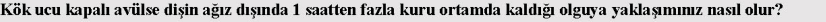 } \\
\hline Kendim müdahale ederim. & $16(28,6)$ & $19(45,2)$ & $12(52,2)$ & \multirow{2}{*}{0,085} \\
\hline Müdahale etmesi için uzmana yönlendiririm. & $40(71,4)$ & $23(54,8)$ & $11(47,8)$ & \\
\hline \multicolumn{5}{|c|}{$\begin{array}{l}\text { Kök ucu kapalı avülse dişin ağız dışında } 1 \text { saatten fazla kuru ortamda kaldığ olguda tedavi yaklaşımmız nasıl } \\
\text { olur? }\end{array}$} \\
\hline $\begin{array}{l}\text { Disis hemen reimplante ederek } 4 \text { hafta boyunca esnek splint } \\
\text { uygular ve } 7-10 \text { gün içerisinde kanal tedavisine başlantm. }\end{array}$ & $3(5,4)$ & $1(2,4)$ & $0(0)$ & \multirow{4}{*}{$<0,001$} \\
\hline $\begin{array}{l}\text { Disis \% 2'lik NaF ya da Doksisiklin cözzeltisinde beklettikten sonra } \\
\text { reimplante edip } 4 \text { hafta boyunca rijit splint uygular ve } 7-10 \text { gün } \\
\text { içerisinde kanal tedavisine bașlarmm. }\end{array}$ & $13(23,2)$ & $4(9,5)$ & $9(39,1)$ & \\
\hline $\begin{array}{l}\text { Disis \% } 2 \text { 'lik NaF ya da Doksisiklin çözeltisinde beklettikten sonra } \\
\text { reimplante edip } 4 \text { hafta boyunca esnek splint uygular ve 7-10 gün } \\
\text { içerisinde kanal tedavisine bașlarmm. }\end{array}$ & $26(46,4)$ & $33(88,1)$ & $11(47,8)$ & \\
\hline Bilmiyorum. & $14(25)$ & $0(0)$ & $3(13,9)$ & \\
\hline
\end{tabular}

'Kök ucu açık avülse dişin ağız dışında 1 saatten az kuru ortamda kaldığı olguya yaklaşımınız nasıl olur?', 'Kök ucu açık avülse dişin ağız dışında 1 saatten az kuru ortamda kaldığı olgudaki tedavi yaklaşımınız nasıl olur?', 'Kök ucu açık avülse dişin ağız dışında 1 saatten fazla kuru ortamda kaldığı olguya yaklaşımınız nasıl olur?' ve 'Kök ucu açık avülse dişin ağız dışında 1 saatten fazla kuru ortamda kaldığı hastada tedavi yaklaşımınız nasıl olur?' sorularına verilen cevaplar ile diş hekimliği eğitim seviyesi arasında anlamlı bir ilişki gözlenmedi ( $p>0,05)$. Ancak kök ucu kapalı avülse dişin ağız dışında 1 saatten az $(p=0,004)$ ve 1 saatten fazla $(p<0,001)$ kuru ortamda kaldığı olgularda diş hekimlerinin tedavi yaklaşımları ile eğitim seviyeleri arasındaki ilişkinin istatistiksel olarak anlamlı olduğu görüldü.

Tablo 4 klinikte sıkça karşılaşılan dental travma tiplerini içeren olgu fotoğraflarını göstermektedir. 
Tablo 4. Dis hekimlerinin dental travma hakkındaki olgu fotoğraflarına yönelik sorulara verdikleri cevapların dağılımı.

\begin{tabular}{|c|c|c|c|c|}
\hline & $\begin{array}{c}\text { Genel Dis } \\
\text { Hekimi } \\
\text { n }(\%)\end{array}$ & $\begin{array}{c}\text { Uzmanllk } \\
\text { Ögrencisi } \\
\text { n (\%) }\end{array}$ & $\begin{array}{l}\text { Uzman } \\
\mathbf{n}(\%)\end{array}$ & p değeri \\
\hline \multicolumn{5}{|c|}{ Resim 1'de 11 ve 21 numaralı dişlerinde mine krrığ olduğu görülen hastaya yaklaşımımz nasıl olur? } \\
\hline $\begin{array}{l}\text { Müdahale ederim. } \\
\text { Müdahale etmesi icin uzmana yơ̈lendiririm. }\end{array}$ & $\begin{array}{c}56(100) \\
0(0)\end{array}$ & $\frac{34(81,0)}{8(19,0)}$ & $\begin{array}{l}11(47,8) \\
12(52,2)\end{array}$ & $<0,001 *$ \\
\hline \multicolumn{5}{|l|}{ Resim 1'deli hastaya tedavi yaklaşımınız nasıl olur? } \\
\hline Herhangi bir müdahalede bulunmam, takip ederim. & $0(0)$ & $0(0)$ & $1(4,3)$ & \multirow{4}{*}{$0,027^{*}$} \\
\hline Mölleme yapanm. & $10(17,9)$ & $18(42,9)$ & $8(34,8)$ & \\
\hline Kompozit rezin ile restore ederim. & $46(82,1)$ & $23(54,8)$ & $14(60,9)$ & \\
\hline Bilmiyorum. & $0(0)$ & $1(2,4)$ & $0(0)$ & \\
\hline \multicolumn{5}{|c|}{ Resim 2' de 21 numaralı dişinde komplike olmayan kuron kırığı olduğu görülen hastaya yaklaşımını nasıl olur? } \\
\hline Müdahale ederim. & $53(94,6)$ & $31(73,8)$ & $10(43,5)$ & \multirow[t]{2}{*}{$<0,001^{*}$} \\
\hline Müdahale etmesi için uzmana yönlendiririm. & $3(5,4)$ & 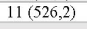 & & \\
\hline \multicolumn{5}{|l|}{ Resim 2' deki hastaya tedavi yaklaşımııı nasıı olur? } \\
\hline Diși kompozit rezin ile restore ederim. & $55(98,2)$ & $40(95,2)$ & $22(95,7)$ & \multirow{3}{*}{0,624} \\
\hline $\begin{array}{l}\text { lunmam, takip eder ve } 18 \\
\text { m. }\end{array}$ & $0(0)$ & $1(2,4)$ & $1(4,3)$ & \\
\hline Bilmiyorum. & $1(1,8)$ & $1(2,4)$ & $0(0)$ & \\
\hline \multicolumn{5}{|c|}{ Resim 3' de 21 numaralı dişinde sublüksasyon yaralanması olduğu görülen hastaya yaklaşımmız nasıl olur? } \\
\hline Müdahale ederim. & $33(58,9)$ & $26(61,9)$ & $12(52,2)$ & \multirow{2}{*}{0,747} \\
\hline Müdahale etmesi için uzmana yönlendiririm. & $23(4$ & & & \\
\hline \multicolumn{5}{|l|}{ Resim 3 'deli hastaya tedavi yaklaşımmıı nasıl olur? } \\
\hline $\begin{array}{l}\text { Herhangi bir müdahalede bulunnam, yumuşak diyet tavsiye } \\
\text { ederim. }\end{array}$ & $13(23,2)$ & $7(16,7)$ & $5(21,7)$ & \multirow{4}{*}{0,082} \\
\hline 2 hafta boyunca rijit splint uygularmm. & $14(25,0)$ & $2(4,8)$ & $6(26,1)$ & \\
\hline 2 hafta boyunca & & & & \\
\hline Bilmiyorum. & $4(7,1)$ & $2(4,8)$ & $1(4,3)$ & \\
\hline \multicolumn{5}{|c|}{ Resim 4'de 21 numaralı dişinde ekstrüzyon yaralanması olduğu görülen hastaya yaklaşıımıız nasl olur? } \\
\hline 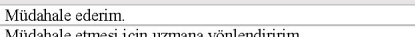 & $22(39,3)$ & $23(54,8)$ & $\frac{12(52,2)}{11(478)}$ & \multirow[t]{2}{*}{0,273} \\
\hline Müdahale etmesi için uzmana yörlendiririm. & $34(60,7)$ & & $11(47,8)$ & \\
\hline \multicolumn{5}{|l|}{ Resim 4' deki hastaya tedavi yaklaşımımı nasıl olur? } \\
\hline Dişi repoze edip 2 hafta boyunca esnek splint uygularım. & $34(60,7)$ & $38(90,5)$ & $14(60,9)$ & \multirow{3}{*}{$0,004^{*}$} \\
\hline & & & & \\
\hline Bilmiyorum. & $9(16,1)$ & $1(2,4)$ & $1(4,3)$ & \\
\hline \multicolumn{5}{|c|}{ Resim 5a-b'de 21 numaralı dişinde intrüzyon yaralanmass olduğu görülen hastaya yaklaşıımmzz nasıl olur? } \\
\hline Müdahale ederim. & & & & \multirow{2}{*}{$0,018^{*}$} \\
\hline Müdahale etmesi için uzmana yörlendirinim. & $49(87,5)$ & $29(69,0)$ & & \\
\hline \multicolumn{5}{|l|}{ Resim 5a-b'deki hastaya tedavi yaklaşımını nassl olur? } \\
\hline Spontan re-erüpsiyon & $15(26$, & $21(50,0)$ & $13(56,5)$ & \multirow{4}{*}{$0,004^{*}$} \\
\hline & & $11(26$ & & \\
\hline Ortodontik repo & $8(14,3)$ & $3(7,1)$ & $7(30$ & \\
\hline & $17(30,4)$ & $7(16,7)$ & $1(4,3)$ & \\
\hline \multicolumn{5}{|c|}{$\begin{array}{l}\text { Resim 6a-b’de alveol kemiğin bukkal segmentinde krrk olduğu görülen süt dişlenme dönemindeki hastaya } \\
\text { yaklaşmumz nassl olur? }\end{array}$} \\
\hline Müdahale ederim. & $4(7,1)$ & $14(33,3)$ & & \multirow{2}{*}{$0,002^{*}$} \\
\hline Müdahale ettmesi için uzmana yö̈lendiririm. & $52(92,9)$ & $28(66,7)$ & $15(65,2)$ & \\
\hline \multicolumn{5}{|l|}{ Resim 6a-b'deki hastaya tedavi yaklaşımını nassl olur? } \\
\hline 2 hafta boyunca tijit splint uygularm. & 3( & $1(2,4)$ & $2(8,7)$ & \multirow{4}{*}{$0,013^{*}$} \\
\hline 4 hafta boyunca rij & $25(44,6)$ & $23(54,8)$ & $13(5$ & \\
\hline 4 hafta boyunca esnek splint uygularmm. & $9(16,1)$ & $15(35,7)$ & $6(26,1)$ & \\
\hline Bilmiyorum. & $19(33,9)$ & $3(7,1)$ & $2(8,7)$ & \\
\hline
\end{tabular}

\section{ki kare testi; $p<0,05$}
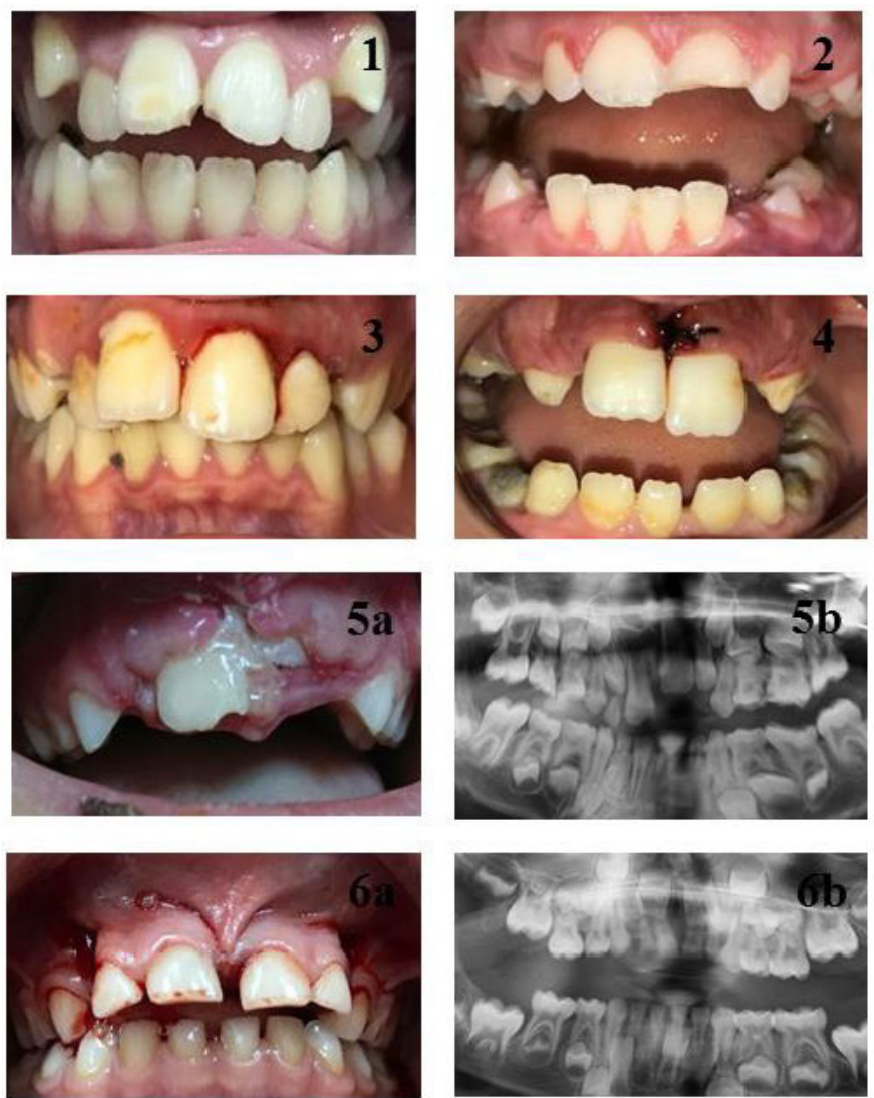

Resim 1. Mine kırığı, Resim 2. Komplike olmayan kuron kırığı, Resim 3. Sub lüksasyon yaralanması, Resim 4. Ekstrüziv lüksasyon yaralanması, Resim 5a-b. Intrüziv lüksasyon yaralanması, Resim 6a-b. Alveol kırığı
Resim 1'de 11 ve 21 numaralı dişlerinde mine kırığı $(p<0,001)$ ve Resim 2 'de 21 numaralı dişinde komplike olmayan kuron kırığı $(p<0,001)$ olduğu görülen hastalara 'Müdahale ederim.' cevabını veren genel diş hekimi sayısının uzman ve uzmanlık öğrencilerine kıyasla istatistiksel açıdan anlamlı derecede yüksek olduğu tespit edildi. Resim 1'de görülen mine kırığında hekimlerin tedavi yaklaşımlarının sorgulandığı soruya genel diş hekimlerinin daha yüksek oranda doğru cevabı verdiği saptandı $(p=0,027)$. Resim 2 ve $3^{\prime}$ te yer alan olgulara tedavi yaklaşımları sorulan hekimlerin verdikleri cevapların benzer olduğu görüldü. Resim 3 ve Resim 4 'te görülen sublüksasyon ve ektrüzyon yaralanmaları karşısında hekimlerin müdahale durumları ile eğitim seviyeleri arasında istatistiksel olarak anlamlı bir fark gözlenmedi ( $p>0,05)$.

Resim 4'te 21 numaralı dişinde ekstrüzyon yaralanması olduğu görülen olguda uzmanlık öğrencilerinin büyük kısmının $(\% 90,5)$ doğru tedavi yaklaşımı olan 'Diş repoze edilir, 2 hafta esnek splint yapılır.' ifadesini seçtiği belirlendi $(p=0,004)$. Resim $5 a-b$ ve $6 a-b^{\prime} d e$ sirasıyla intrüzyon ve alveol kemiğinin bukkal segmentinde kırık olduğu görülen olgular karşısında genel diş hekimlerinin büyük bölümünün 'Müdahale etmesi için uzmana yönlendiririm.' cevabını verdiği tespit edildi $(p=0,018 ; p=0,002)$. Resim 5a-b'de yer alan olguda uzman diş hekimlerinin $\% 56,5$ 'nin diğer gruplara nazaran istatistiksel açıdan anlamlı derecede spontan re-erüpsiyon seçeneğini tercih ettiği görüldü ( $p=0,004)$. Resim 6a-b'de alveol kemiğinde kırık olduğu gözlenen olguda uzman diş hekimlerinin \% 56,5 'nin '4 hafta süreyle rijit splint yapılır.' cevabını verdiği tespit edildi $(p=0,013)$.

Süt dişlerinde görülen travmatik yaralanmalar ile ilgili Tablo $5^{\prime}$ te sorulan

Tablo 5. Diş hekimlerinin süt dişi dental yaralanmalar ile ilgili sorulara verdikleri cevapların dağılımı.

\begin{tabular}{|c|c|c|c|c|}
\hline & $\begin{array}{c}\text { Genel Dis } \\
\text { Helimi } \\
\text { n(\%) }\end{array}$ & $\begin{array}{c}\text { Uzmanhlk } \\
\text { Öğrencisi } \\
\text { n(\%) }\end{array}$ & $\begin{array}{l}\text { Uzman } \\
\mathbf{n}(\%)\end{array}$ & $p$ değeri \\
\hline \multicolumn{5}{|c|}{ Süt dişi lateral lüksasyon yaralanmalarında, diş kökünün labiale yer değiştirdiği durumda yaklaşımmız nasıl olur? } \\
\hline Müdahale ederim. & $34(60,7)$ & $27(64,3)$ & $10(43,5)$ & \multirow{2}{*}{0,243} \\
\hline Müdahale etmesi için uzmana yönlendiririm. & $22(39,3)$ & $15(35,7)$ & $13(56,5)$ & \\
\hline \multicolumn{5}{|c|}{$\begin{array}{l}\text { Süt dişi lateral lüksassyon yaralanmalarında, diş kökünün labiale yer değiştirdiği durumda tedavi yaklaş̧mmız nasıl } \\
\text { olur? }\end{array}$} \\
\hline Süt dișini çekerim. & $8(14,3)$ & $17(40,5)$ & $1(4,3)$ & \multirow{4}{*}{0,007} \\
\hline Süt disinini repoze edip soket içerisinde brrakırmm. & $12(21,4)$ & $7(16,7)$ & $9(39,1)$ & \\
\hline $\begin{array}{l}\text { Süt disinin repoze edip } 2 \text { hafta boyunca esnek splint } \\
\text { uvgularmm. }\end{array}$ & $24(42,9)$ & $14(33,3)$ & $10(43,5)$ & \\
\hline Bilmiyorum. & $12(21,4)$ & $4(9,5)$ & $3(13,0)$ & \\
\hline \multicolumn{5}{|c|}{ Süt dişi ekstrüzyon yaralanmalarında, 3 mm' den fazla yer değiştirmenin olduŏu durumda yaklaşmınz nasıl olur? } \\
\hline Müdahale ederim. & $27(48,2)$ & $23(54,8)$ & $10(43,5)$ & \multirow{2}{*}{0,659} \\
\hline Müdahale etmesi için uzmana yönlendiririm. & $29(51,8)$ & $19(45,2)$ & $13(56,5)$ & \\
\hline \multicolumn{5}{|c|}{$\begin{array}{l}\text { Süt dişi ekstrüzyon yaralanmalarmda } 3 \text { mm' den fazla yer değiştirmenin olduğu durumda tedavi yaklaşmmmı nast } \\
\text { olur? }\end{array}$} \\
\hline Süt dişini çekerim. & $28(50,0)$ & $33(78,6)$ & $18(78,3)$ & \multirow{3}{*}{0,013} \\
\hline Süt disini repoze edip 2 hafta boyunca esnek splint & $18(32,1)$ & $6(14,3)$ & $5(21,7)$ & \\
\hline Bilmiyorum. & $10(17,9)$ & $3(7,1)$ & $0(0)$ & \\
\hline \multicolumn{5}{|c|}{ Süt dişi avülsiyon yaralanmasyyla karşlaştı̆̆mızda yaklaşımmız nasıl olur? } \\
\hline Müdahale ederim. & $35(62,5)$ & $30(71,4)$ & $11(47,8)$ & \multirow{2}{*}{0,170} \\
\hline Müdahale etmesi için uzmana yönlendiririm. & $21(37,5)$ & $12(28,6)$ & $12(52,2)$ & \\
\hline \multicolumn{5}{|c|}{ Süt dişi avüllsiyon yaralanma sıyla karşılaştğı̆mzda tedavi yaklaş̧mıız nasıı olur? } \\
\hline Hiçbir müdahalede bulummam. & $35(62,5)$ & $37(88,1)$ & $15(65,2)$ & \multirow{4}{*}{0,017} \\
\hline $\begin{array}{l}\text { Süt dişini reimplante edip } 2 \text { hafta boyunca rijit splint } \\
\text { uygularım. }\end{array}$ & $0(0)$ & $0(0)$ & $1(4,3)$ & \\
\hline $\begin{array}{l}\text { Süt disini reimplante edip } 2 \text { hafta boyunca esnek splint } \\
\text { uvgulartm. }\end{array}$ & $8(14,3)$ & $3(7,1)$ & $5(21,7)$ & \\
\hline Bilmiyorum. & $13(23,2)$ & $2(4,8)$ & $2(8,7)$ & \\
\hline
\end{tabular}

'Süt dişi lateral lüksasyon yaralanmalarında dişin kökünün labiale yer değiştirdiği durumda ne yaparsınız?' ve 'Süt dişi ekstrüzyon yaralanmalarında $3 \mathrm{~mm}$ 'den fazla yer değiştirmenin olduğu durumda ne yaparsınız?' sorularına 
verilen cevaplar ile diş hekimliği eğitim seviyesi arasında anlamlı bir fark gözlenmedi. Süt dişi lateral lüksasyon yaralanmalarında diş kökünün labiale yer değiştirdiği olguda uzmanlık öğrencilerine kıyasla diğer diş hekimlerinin istatistiksel olarak anlamlı derecede süt dişini repoze ederek 2 hafta esnek splint uyguladıkları belirlendi $(p=0,007)$. Süt dişinin $3 \mathrm{~mm}$ 'den fazla ekstrüze olduğu olguda uzman diş hekimlerinin \% 78,3'ünün ve uzmanlık öğrencilerinin $\% 78,6$ 'sının ilgili dişin çekilmesi gerektiği yanıtını verdiği saptandı $(p=0,013)$. 'Süt dişi avülsiyon yaralanmasıyla karşılaşı̆̆ınızda tedavi yaklaşımınız nasıl olur?' sorusuna uzmanlık öğrencilerinin büyük kısmının $(\% 88,1)$ 'Hiçbir müdahalede bulunmam.' cevabını verdiği gözlendi ( $p=0,017$ ).

Anket uygulaması sonrasında, çalışmada yer alan diş hekimlerine dental travma ile ilgili eğitim almak ister misiniz sorusu yöneltildiğinde hekimlerin $\% 67,1^{\prime} i$ eğitim almak istediğini belirtti.

\section{TARTIŞMA}

TDY'ler etkili, doğru, hızlı tedavi ve uygun takip prosedürleri gerektiren olgulardır. Hekimlerin bilgi düzeyleri uygun tedavi planlamasında önem taşımakta ve prognozu doğrudan etkilemektedir13. Yapılan literatür incelemesinde Karadeniz Bölgesi'nde diş hekimlerinin TDY konusundaki bilgi düzeylerini değerlendiren bir çalışma ile karşılaşılmadı. Bu çalışma Rize ilinde görev yapmakta olan diş hekimlerinin dental travma karşısında acil müdahale bilgi, beceri ve tutumunu değerlendirerek farkındalık oluşturmak, eksik ve yetersiz bilinen konuları saptayarak eğitim almak isteyen hekimlerin bilgi eksikliklerini gidermek amacıyla gerçekleştirildi.

Diş hekimlerinin dental bilgi düzeylerinin değerlendirildiği çalışmalarda farklı sonuçlar rapor edilmiştir. Alyasi ve ark.'nın ${ }^{7}$ Birleşik Arap Emirlikleri'nde, Zaleckiene ve ark.'nın ${ }^{14}$ Litvanya'da, De França ve ark.'nın ${ }^{15}$ Brezilya'da, Kostopoulou ve ark.'nın ${ }^{16}$ Ingiltere'de gerçekleştirdikleri çalışmalarda diş hekimlerinin bilgi düzeyleri yetersiz görülürken; Buldur ve ark.'nın ${ }^{5}$ Türkiye'de, Akhlaghi ve ark.'nın ${ }^{17}$ İran'da, Yeng ve ark.'ın ${ }^{18}$ Avusturalya'da gerçekleştirdikleri çalışmalarda diş hekimlerinin orta düzeyde dental travma bilgisine sahip oldukları tespit edilmiştir. Benzer sonuçlar elde edilememesinin nedenleri arasında çalışmaların farklı ülkelerde gerçekleşmesi ve katıımcıların mesleki deneyim sürelerinin aynı olmaması sayılabilir. De França ve ark..$^{15}$ mesleki deneyim süresi 10 yıl ve daha az olan hekimlerin, 10 yıldan fazla olanlara göre bilgi düzeylerinin daha yüksek olduğunu rapor etmiştir. Mevcut çalışma Sivas ilinde Buldur ve ark. ${ }^{5}$ tarafından gerçekleştirilen araştırmanın sonuçları ile benzerlik göstermektedir. Türkiye'deki diş hekimliği fakültelerinde benzer eğitimlerin verilmesi, her iki ilde de görev yapan diş hekimlerinin genç olmaları ve bilgilerinin güncelliklerini korumaları benzer sonuçlar elde edilmesinde etkili olabilir.
TDY'de artmış mobiliteyi engellemek veya dişlere etki eden kuvvetlerin yönünü modifiye edebilmek amacıyla travma splintlerine intiyaç duyulabilmektedir. ${ }^{19}$ Ortodontik ligatür teli, kompozit rezin, titanyum ve fiber dental travma olgularında en sık tercih edilen splint materyalleri arasında yer almaktadır. ${ }^{20}$ Brezilya'da gerçekleştirilen bir araştırmada hekimlerin \% 73'ü semi-rijit naylon teli, \% 10'u çelik teli, \% 10'u kompoziti splint materyali olarak kullanmayı tercih ettiklerini bildirmişlerdir. ${ }^{13} \mathrm{Bu}$ çalışmada ise genel diş hekimlerinin \%48, 1 'inin kompozit rezini, uzmanlık öğrencilerinin \% 69,6'sının fiberi ve uzmanların \%53,3'ünün ligatür telini splint materyali olarak tercih ettiği görüldü. Hekimler arasındaki splint materyali tercihinin farklıık göstermesi, hekimlerin kolay ulaşabileceği materyali tercih etmesinden kaynaklanabilir. Özel muayenehane veya devlet hastanelerinde çalışan genel diş hekimlerinin en kolay ulaşabileceği splint materyali restorasyonlarda da sıklıkla tercih edilen kompozit rezindir. Uzmanlık öğrencileri eğitim ve araştırma faaliyetlerinin de yürütüldüğü üniversite hastanelerinde görev yapmakta ve fiber içerikli materyallere kolayca ulaşabilmektedir. Uzman hekimlerin arasında ortodonti uzmanlarının bulunmasının ortodontik ligatür telinin tercih edilme nedenlerinden biri olabileceği düşünülmektedir.

Avülsiyon olguları TDY'nin \% 0.5-16'sını oluşturmaktadır. ${ }^{21,22}$ Avülsiyon tipi yaralanmalar kök gelişiminin tamamlanmadığı 7-10 yaşlarında ve özellikle üst kesici dişlerde daha sık görülmektedir ${ }^{23}$. Bu durum dişin vitalitesinin korunması açısından acil müdahale intiyacını arttırmaktadır. Bu çalışmada 'Kök ucu kapalı avülse dişin ağız dışında 1 saatten az kuru ortamda kaldığı olgudaki tedavi yaklaşımınız nedir?' sorusuna diş hekimlerinin \%69,4'ü doğru cevap verirken, 1 saatten fazla kuru ortamda kaldığı durumlardaki tedavi yaklaşımına doğru cevap veren hekimlerin oranı $\% 58,3$ olarak belirlendi. Genel diş hekimlerinin doğru cevap verme oranlarının ise daha düşük olduğu görüldü. $(p<0,001)$. Yanlış cevap veren hekimlerin splint tercihinde hata yaparak rijit splinti tercih ettikleri tespit edildi. Yapılan çalışmalarda rijit splintlemelerin periodontal ligamentte baskı oluşturarak neoanjiogeneziste problemlere ve ankiloza sebep olabileceği gösterilmiştir ${ }^{24}$. Diş hekimlerinin TDY konusundaki bilgilerinin araştırıldığı benzer çalışmalarda da bilgi eksikliklerinin görüldüğü rapor edilmiştir.7,12,15,17

Epidemiyolojik çalışmaların bulguları TDY'lerin büyük bir kısmının mine tabakası ile sınırlı olduğunu göstermektedir. ${ }^{25}$ Mine ile sınırlı basit kırıklarda kabul edilen tedavi yönteminin mölleme veya restorasyon olduğu bilinmektedir3. Çalışmaya katılan genel diş hekimlerinin $\% 100$ 'ü, uzmanlık öğrencilerinin $\% 81^{\prime} i$, uzman diş hekimlerinin ise $\% 47,8^{\prime} i$ mine kırıklarına müdahale edeceğini bildirdi. Uzman hekimlerin olguyu ilgili uzmana yönlendirme oranının daha yüksek olduğu görüldü $(p<0,001)$. Restoratif 
işlem gerektiren durumlarla ilgili diğer sorularda da benzer sonuçlar ile karşılaşıldı. Bu durum çalışmaya katılan uzman hekimler arasında, Ağız Diş ve Çene Cerrahisi, Ağız Diş ve Çene Radyolojisi, Ortodonti, Periodontoloji ve Protetik Diş Tedavisi uzmanları gibi rutin işlemleri arasında restoratif tedaviler bulunmayan uzmanların restoratif müdahalede bulunmamayı tercih etmeleri ile açıklanabilir. Pulpa odasının kırık hattı sınırları dahilinde bulunmadığı, mine ve dentinin birlikte etkilendiği komplike olmayan kuron kırıkları şiddetli ağrılara neden olmamakla birlikte, açığa çıkan dentin tübüllerinden bakteriyel penetrasyon, pulpa dejenerasyonu ve nekrozuna neden olabileceğinden bu tip dental travmaların tespit ve tedavileri önem taşımaktadır. ${ }^{26}$ Komplike olmayan kuron kırıklarında farklı tedavi seçenekleri bulunsa da estetik ve fonksiyonu en ideal şekilde karşılayabilmek için mevcut ise kırık parçanın reataçmanı tercih edilmektedir. ${ }^{27}$ Kırık parçanın bulunamadığı durumlarda uygun restoratif materyal ile travmaya maruz kalan bölgenin restorasyonu gerekmektedir. Açık dentin yüzeyinin kapatımasını takiben daimi restorasyon yapımı da önerilen tedavi yöntemleri arasında yer almaktadır. ${ }^{28}$ Çalışmada komplike olmayan kuron kırığının tedavisi ile ilgili soruya hekimlerin \%96,7'sinin doğru cevap verdiği görüldü. Ancak genel diş hekimlerinin $\% 94,6$ 'sı ve uzmanlık öğrencilerinin \%73,8'i kendisinin müdahale edebileceğini, uzman hekimlerin ise $\% 56,5^{\prime}$ i müdahale etmesi için uzmana yönlendireceğini belirtti $(p<0,001)$. Komplike olmayan kuron kırıkları ile ilgili bulgular benzer çalışmaları desteklemektedir.7,12,15

Parsiyel avülsiyon olarak da tanımlanan ekstrüziv lüksasyon yaralanmaları dişin parsiyel olarak soketinden ayrıması olarak tanımlanmaktadır ${ }^{29}$. Tedavi yaklaşımında dişin en kısa sürede soket içerisine repozisyonu ve esnek bir splint materyali ile stabilizasyonu önem taşımaktadır. Kök kanal tedavisi apeksi kapalı olan dişlerde ve nekroz bulgusu bulunan açık apeksli dişlerde endikedir. ${ }^{30}$ Çalışmada ilgili soruya genel diş hekimlerinin $\% 60,7^{\prime} \mathrm{si}$, uzmanlık öğrencilerinin $\% 90,5^{\prime} \mathrm{i}$, uzman hekimlerin ise $\% 60,9^{\prime} \mathrm{u}$ doğru cevap verirken, genel diş hekimlerinin çoğunluğunun olguyu bir uzmana göndermeyi tercih ettiği görüldü. Akhlaghi ve ark.'nın ${ }^{17}$ araştırmasına benzer şekilde bu çaış̧manın bulguları özellikle genel diş hekimlerinin teorik bilgileri yeterli olsa bile, olguyu bir uzmana yönlendirmeyi tedavi etmeye tercih ettiklerini göstermektedir.

Daimi dişin soket içerisine gömülmesi ile görülen intrüziv lüksasyon yaralanmaları en az rastlanan TDY tipi olmasına rağmen oluşturabileceği fonksiyonel, estetik ve ortodontik komplikasyonlar nedeniyle önem arz etmektedir. ${ }^{31}$ Kök gelişim aşaması ve intrüzyonun şiddetine göre 3 farklı tedavi yaklaşımı bulunmaktadır. Bunlar spontan, ortodontik veya cerrahi ekstrüzyondur. ${ }^{31}$ Kök gelişimini tamamlamamış intrüziv yaralanma olgusunda hekimlerin büyük çoğunluğunun $(\% 76,0)$ müdahale etmesi için uzmana yönlendirmeyi tercih ettiği görüldü. Tedavi yaklaşımında spontan re-erüpsiyonun tercih edilmesi gereken olguda genel diş hekimlerinin sadece $\% 26,8^{\prime} i$, uzmanlık öğrencilerinin $\% 50$ 'si, uzman diş hekimlerinin ise $\% 56,5^{\prime}$ inin doğru yanıt verdiği görüldü. Genel diş hekimlerinin intrüziv yaralanmalar konusundaki bilgi düzeylerinin daha düşük olduğu belirlendi $(p=0,004)$. Çalışmanın sonuçlarına benzer olarak diş hekimlerinin intrüzyon konusunda yetersiz bilgi sahibi olduklarını rapor eden araştırmalar bulunmaktadır. ${ }^{5,72,14}$ Fakat İran'da yapılan bir araştırmada intrüze olmuş bir olguda acil tedavi yaklaşımı sorgulanmış ve çaıışmaya katılan genel diş hekimlerinin \%54,4'ü doğru cevap vermiştir. ${ }^{17}$ Litvanya'lı diş hekimleri ile yapılan başka bir çalışmada, apeksi açık bir dişin yaklaşık $5 \mathrm{~mm}$ intrüze olması durumuyla ilgili hekimlerin çoğu doğru cevap vermiştir. ${ }^{14}$ Çalışmada yer alan hekimlerin intrüziv dental yaralanmalar konusundaki bilgi düzeylerinin düşük olması bu tip dental travmaların nadir görülmesi ile açıklanabilir.

Alveoler proses kırıkları çenelerin bazal kısımlarında oluşan kırıklar ve/veya dişlerin lüksasyonları ile ilişkili meydana gelmektedir. ${ }^{32} \mathrm{Bu}$ tip yaralanmaların tedavisinde repozisyon ve 4 hafta süreyle rijit splintleme yer almaktadır. ${ }^{30}$ Çalışmada bukkal segmentinde kırık bulunan hastada tedavi yaklaşımı soruldu ve hekimlerin $\% 48,8^{\prime} i$ doğru cevap olan "4 hafta süre ile rijit splint yapııır." cevabını seçerken, $\% 24,8$ 'inin "4 hafta süre ile esnek splint yapılır" seçeneğini tercih ettiği görüldü. Uzman diş hekimlerinin doğru cevap verme oranlarının anlamlı derecede daha fazla olduğu tespit edildi $(p=0,013)$. Genel diş hekimlerinin çoğunluğu $(\% 78,5)$ alveoler proses kırıklarında müdahale etmeyerek ilgili uzman hekime yönlendireceğini belirtti. Alveoler proses kırıkları ile ilgili tespit edilen bilgi eksikliği Hartmann ve ark..$^{2}$ tarafından yapılan katıımcıların yarısından fazlasının yanlış cevap verdiği kemik kırıkları ile ilgili araştırma ile benzerlik göstermektedir.

Süt dişlerinde görülen travmatik dental yaralanmalar 2-3 yaş aralığındaki çocukları sıklıkla etkilemekte ve daimi dişlerin prognozu tedavi planlamasında en büyük kaygıyı oluşturmaktadır. ${ }^{33,34}$ Süt dişlerinde en yaygın görülen travma tipinin lüksasyon yaralanmaları olduğu rapor edilmiştir. ${ }^{35,36}$ Costa ve ark., sublüksasyonun süt dişlerinde en sık karşılaşılan lüksasyon yaralanmalarından biri olduğunu göstermiştir. ${ }^{37}$ Yer değiştirmenin derecesine bağlı olarak farklı tedavi seçenekleri önerilmektedir. ${ }^{30}$ Assunçao ve ark. ${ }^{36}$ en yaygın kabul gören tedavi protokolünün yalnızca takip etmek olduğunu belirtmiştir. Ravikumar ve ark. ${ }^{9}$ genel diş hekimlerinin süt dişleri ile ilgili dental travma bilgisini değerlendirdikleri bir araştırmada, 3 yaşında palatinale doğru lükse olan, okluzal interferansı bulunmayan ve ciddi okluzal interferansı bulunan olgular karşısında hekimlerin büyük çoğunluğunun doğru cevap verdiklerini belirtmiştir. Bu çalışmada ise, süt dişlerinde lateral lüksasyon tipi yaralanmalar karşısında hekimlerin büyük 
çoğunluğunun müdahalede bulunduğu, ancak bu konudaki travma bilgilerinin yeterli olmadığı görüldü. Farklı ülkelerde yapılan araştırmaların sonuçlarına benzer şekilde, süt dişi ekstrüzyon ve avülsiyon yaralanmaları karşısında doğru tedavi yaklaşımı hakkında, çalışmada yer alan hekimlerin büyük kısmının bilgi sahibi olduğu görüldü. 17,35,36 Ancak süt dişi reimplantasyonunu tercih eden hekimlerin çoğunlukta olduğu çalışmalar da bulunmaktadır.,9 Kapur ve ark., ${ }^{35}$ Assunçao ve ark.36 bu durumu hekimlerin tecrübesi ve lüksasyon ile avülsiyon yaralanmalarının çok sık karşılaşılan travma tipleri olması ile açıklamıştır. Bu çalışmada ise, yeni mezun ve uzmanlık öğrencisi olan diş hekimlerinin yeni materyaller ve dental travma konusunda bilgilerinin güncel olması, ayrıca genç hekimlere kıyasla yaşça büyük hekimlerin literatürü yeterli düzeyde takip etmemesi ile ilişkili olduğu düşünülmektedir. Bu açıdan çaıışma bulgularının Buldur ve ark. ${ }^{5}$ tarafından 2018 yılında Sivas'ta yapılan araştırmanın sonuçları ile desteklendiği görülmektedir. Bununla birlikte çalışmaya katılan hekimlerin süt dişi dental yaralanmalarına, travma bilgileriyle orantılı olarak herhangi bir müdahalede bulunmadığı; böyle bir durum karşısında, müdahale etmesi için uzman hekime yönlendirdiği tespit edildi.

Eden ve ark. ${ }^{38}$ tarafından yapılan araştırmada yer alan hekimlerin $\% 67,1^{\prime} i$ dental travma ile ilgili bir eğitim programına katılmak ister misiniz sorusuna evet yanıtını vermiştir. Benzer şekilde, bu çalışmadaki hekimlerin büyük çoğunluğu ( $n=107$ ) bu konuda eğitim almak istediğini belirtti. Çalışma kapsamında anket uygulaması sonrası isteyen hekimlere dental travma hakkında yüz yüze sunum yapılarak eğitim verildi.

\section{SONUÇ}

Sonuç olarak, Rize ilinde görev yapmakta olan diş hekimlerinin travmatik dental yaralanmaların pek çoğu hakkında bilgi seviyelerinin yeterli olduğu görüldü. Hekimlerin büyük çoğunluğunun daimi dişlerde karşılaşılan ekstrüzyon, intrüzyon, kök ucu açık ve kapalı avülsiyon, alveol kemikte kııık ve süt dişi ekstrüzyon olgularına yapılması gereken doğru tedavi yaklaşımını bildiği, bununla birlikte bu olguları müdahale etmesi için uzman hekime yönlendirdiği görüldü. Bu durumun katılımcıların klinik tecrübeleri, çalıştıkları kliniklerin hasta yoğunlukları, malzeme eksiklikleri ve dental travma deneyimleri ile ilişkili olabileceği düşünülmektedir. Bu çalışmanın sınırları dahilinde; diş hekimlerine müdahale etmekten kaçındıkları travma olguları hakkında teorik ve uygulamalı eğitimlerin verilmesi önerilebilir.

\section{KAYNAKLAR}

1. Altun C, Ozen B, Esenlik E, Guven G, Gürbüz T, et al. Traumatic injuries to permanent teeth in Turkish children, Ankara. Dent Traumatol 2009; 25: 309-313.

2. Soriano EP, Caldas Jr AdF, Carvalho MVDD, Amorim Filho HD. Prevalence and risk factors related to traumatic dental injuries in Brazilian schoolchildren. Dent Traumatol 2007; 23: 232-240.

3. DiAngelis AJ, Andreasen JO, Ebeleseder KA, Kenny DJ, Trope M, et al. International Association of Dental Traumatology guidelines for the management of traumatic dental injuries: 1. Fractures and luxations of permanent teeth. Dent Traumatol 2012; 28: 2-12.

4. Altay N, Güngör HC. A retrospective study of dentoalveolar injuries of children in Ankara, Turkey. Dent Traumatol 2001; 17: 197-200.

5. Buldur B, Kapdan A. Factors Associated with Knowledge and Attitude of Management of Traumatic Dental Injuries: A Cross-Sectional Study among Turkish Dentists. Pesq Bras Odontoped Clin Integr 2018; 18: 3948.

6. Eyuboglu O, Yilmaz Y, Zehir C, Sahin H. A 6 year investigation into types of dental trauma treated in a paediatric dentistry clinic in Eastern Anatolia region, Turkey. Dent Traumatol 2009; 25: 110-114.

7. Alyasi M, Al Halabi M, Hussein I, Khamis A, Kowash M. Dentists' knowledge of the guidelines of traumatic dental injuries in the United Arab Emirates. Eur J Paediatr Dent 2018; 19: 271-276.

8. Re D, Augusti D, Paglia G, Augusti G, Cotti E. Treatment of traumatic dental injuries: evaluation of knowledge among Italian dentists. Eur J Paediatr Dent 2014; 15: 23 28.

9. Ravikumar D, Jeevanandan G, Subramanian E. Evaluation of knowledge among general dentists in treatment of traumatic injuries in primary teeth: A cross-sectional questionnaire study. Eur J Dent. 2017; 11: 232.

10. Aren A, Erdem AP, Aren G, Şahin ZD, Tolgay CG, et al. Importance of knowledge of the management of traumatic dental injuries in emergency departments. Ulus Travma Acil Cerrahi Derg 2018; 24: 136-144.

11. Yigit $Y$, Helvacioglu Yigit $D$, Kan $B$, Ilgen $C$, Yilmaz $S$. Dentofacial traumatic injuries: A survey of knowledge and attitudes among emergency medicine physicians in Turkey. Dent Traumatol 2019; 35: 20-26.

12. Hartmann RC, Rossetti $B R$, Siqueira Pinheiro $L$, Poli de Figueiredo JA, Rossi Fedele G, et al. Dentists $\square$ knowledge of dental trauma based on the International Association of Dental Traumatology guidelines: A survey in South Brazil. Dent Traumatol 2019; 35: 27-32.

13. Westphalen VPD, Martins WD, Deonizio MDA, da Silva Neto UX, Da Cunha CB, et al. Knowledge of general practitioners dentists about the emergency management of dental avulsion in Curitiba, Brazil. Dent Traumatol 2007; 23: 6-8.

14. Zaleckienè V, Pečiulienè V, Brukienè V, Jakaitienė A, Aleksejūnienè J, et al. Knowledge about traumatic dental injuries in the permanent dentition: A survey of Lithuanian dentists. Dent Traumatol 2018; 34: 100-106.

15. De França RÍ, Traebert J, De Lacerda JT. Brazilian den- 
tists' knowledge regarding immediate treatment of traumatic dental injuries. Dent Traumatol 2007; 23: 287-290. 16. Kostopoulou MN, Duggal MS. A study into dentists' knowledge of the treatment of traumatic injuries to young permanent incisors. Int J Paediatr Dent 2005; 15: 10-19.

17. Akhlaghi N, Nourbakhsh N, Khademi A, Karimi L. General dental practitioners' knowledge about the emergency management of dental trauma. Iran Endod J 2014; 9: 251.

18. Yeng T, Parashos PJDT. An investigation into dentists' management methods of dental trauma to maxillary permanent incisors in Victoria, Australia. Dent Traumatol 2008; 24: 443-448.

19. Mazzoleni S, Meschia G, Cortesi R, Bressan E, Tomasi $C$, et al. In vitro comparison of the flexibility of different splint systems used in dental traumatology. Dent Traumatol 2010; 26: 30-36.

20. Andreasen JO, Andreasen FM, Mejare I, Cvek M. Healing of 400 intra-alveolar root fractures. 2. Effect of treatment factors such as treatment delay, repositioning, splinting type and period and antibiotics. Dent Traumatol 2004; 20: 203-211.

21. Abu-Dawoud M, Al-Enezi B, Andersson L. Knowledge of emergency management of avulsed teeth among young physicians and dentists. Dent Traumatol 2007; 23: 348-355.

22. Qazi SR, Nasir KS. First-aid knowledge about tooth avulsion among dentists, doctors and lay people. Dent Traumatol 2009; 25: 295-299.

23. Caglar E, Ferreira LP, Kargul B. Dental trauma management knowledge among a group of teachers in two south European cities. Dent Traumatol 2005; 21: 258-262.

24. Bauss O, Schwestka-Polly R, Schilke R, Kiliaridis S. Effect of different splinting methods and fixation periods on root development of autotransplanted immature third molars. J Oral Maxillofac Surg 2005; 63: 304-310.

25. Freire-Maia FB, Auad SM, Abreu M, Sardenberg F, Martins MT, et al. Prevalence of and factors associated with enamel fracture and other traumas in Brazilian children 8-10 years old. Braz Oral Res 2018; 32: e89.

26. Ünlü N, Karabekiroğlu S, Tunçdemir MT. Travmaya Uğrayan Dişlerdeki Kron Kırıklarında Uygulanan Tedavi Yöntemleri. Turkiye Klinikleri J Dental Sci-Special Topics 2014; 5: 35-40.

27. Pusman E, Cehreli ZC, Altay N, Unver B, Saracbasi O, et al. Fracture resistance of tooth fragment reattachment: effects of different preparation techniques and adhesive materials. Dent Traumatol 2010; 26: 9-15.

28. Olsburgh $S$, Jacoby $T$, Krejci I. Crown fractures in the permanent dentition: pulpal and restorative considerations. Dent Traumatol 2002; 18: 103-115.

29. Lee R, Barrett EJ, Kenny DJ. Clinical outcomes for permanent incisor luxations in a pediatric population. II.
Extrusions. Dent Traumatol 2003; 19: 274-279.

30. International Association of Dental Traumatology. Dental Trauma Guidelines. 2012 https://www.iadt-dentaltrauma.org/guidelines_book2.pdf

31. Diangelis AJ, Andreasen JO, Ebeleseder KA, Kenny DJ, Trope M, et al. International Association of Dental T. International Association of Dental Traumatology guidelines for the management of traumatic dental injuries: 1. Fractures and luxations of permanent teeth. Dent Traumatol 2012; 28: 2-12.

32. Pagadala $S$, Tadikonda DC. An overview of classification of dental trauma. IAIM 2015; 2:157-164.

33. Flores MT, Malmgren $B$, Andersson $L$, Andreasen JO, Bakland LK, et al. International Association of Dental T. Guidelines for the management of traumatic dental injuries. III. Primary teeth. Dent Traumatol 2007; 23: 196-202.

34. Andreason JO, Andreason FM. Textbook and Color Atlas of Traumatic Injuries to the Teeth. 3rd ed. Copenhagen: Munksgaard; 1994. pp. 383-420

35. Kapur A, Goyal A, Gauba K. Replantation of an avulsed primary incisor: Report of a case with favorable outcome. J Postgrad Med Educ Res 2014; 48: 105-108.

36. Assuncao LRD, Ferelle A, Iwakura MLH, do Nascimento LS, Cunha RF. Luxation injuries in primary teeth: a retrospective study in children assisted at an emergency service. Braz Oral Res 2011; 25: 150-156.

37. Costa VP OL, Rosa DP, Cademartori MG, Torriani DD. Crown-root fractures in primary teeth: A case series study of 28 cases. Braz Dent J 2016; 27: 234-238.

38. Eden E, Kılınç G, Ellidokuz H. İzmir ilindeki iki tıp fakültesine devam eden son sınıf öğrencilerinin dental travmaya yaklaşımları. DEÜ Tıp Fak Derg 2011; 25: 31-37. 